\title{
Single Recessive Gene for Multiple Flowering in Summer Squash
}

\author{
Harry S. Paris ${ }^{1}$ and Aviva Hanan \\ Department of Vegetable Crops and Plant Genetics, Agricultural Research \\ Organization, Newe Ya'ar Research Center, P.O. Box 1021, Ramat Yishay \\ 30-095, Israel
}

Additional index words. Cucurbita pepo, mode of inheritance, vegetable breeding

\begin{abstract}
Most summer squash, Cucurbita pepo L., produce one flower bud per leaf axil, whereas some genotypes can produce two or more. The former genotypes are referred to as single-flowering, whereas the latter are referred to as multiple-flowering. The objective was to determine the mode of inheritance of multiple flowering. The zucchini 'True French', which is single-flowering, was crossed with Accession 1777, a nearly isogenic line of this cultivar, which is multiple-flowering. Parental, filial, and back-cross plants were grown in pots in the greenhouse and each of their first 15 leaf axils was scored for the number of flower buds. Nearly all $F_{1}$ plants, regardless of the direction of the cross, and plants resulting from back-crossing to 'True French' were single-flowering. Approximately one-fourth of the $F_{2}$ plants, regardless of the direction of the cross, and half of the plants of the back-cross to 1777 produced two flowers at one or more leaf axils. These results indicate that the ability to produce more than one flower per axil is conferred by a single recessive gene, herewith designated multiple flowering, symbol $\mathrm{mf}$.
\end{abstract}

Summer squash plants are monoecious, producing staminate and pistillate flowers. The flowers are borne at the stem nodes, more precisely at the leaf axils, the junctions of the stem with the bases of the leaf petioles. Staminate flowers differentiate at the first leaf axils. Pistillate flowers differentiate subsequently but develop faster. Consequently, the first staminate and pistillate flowers often attain anthesis simultaneously. After pollination, the pistillate flowers develop into fruits that, under most conditions, are harvested at 2 to $5 \mathrm{~d}$ past anthesis (Paris and Maynard, 2008).

The cultivar-groups of summer squash known as Cocozelle, Vegetable Marrow, and Zucchini are single-flowering, that is, one flower bud is produced per leaf axil. On the other hand, the other cultivar-groups of summer squash known as Crookneck, Scallop, and Straightneck, are multiple-flowering, that is, they can produce two, three, or even four flower buds at leaf axils. Worldwide, the former cultivar-groups are more widely distributed and exceed the latter in economic value (Paris, 1996).

In 1996, the senior author initiated a breeding program with the goal of developing cocozelle and zucchini germplasm able to produce more than one flower per leaf axil. Subsequently, an investigation was undertaken to determine the mode of inheritance of the multiple-flowering trait. The objective of this report is to describe this investigation and its result.

Received for publication 3 Sept. 2010. Accepted for publication 16 Sept. 2010.

${ }^{1}$ To whom reprint requests should be addressed; e-mail hsparis@agri.gov.il.

\section{Materials and Methods}

A plant of Cucurbita pepo subsp. pepo Cocozelle Group 'Striato Pugliese' (Ingegnoli, Milan, Italy), which is single-flowering, was crossed with a plant from an accession of C. pepo subsp. texana Crookneck Group, which is multiple-flowering. An $\mathrm{F}_{1}$ plant was self-pollinated and a resulting multiple-flowering $\mathrm{F}_{2}$ plant was selected and crossed with a plant of a highly inbred line derived from the single-flowering $C$. pepo subsp. pepo Zucchini Group 'True French' (Thompson \& Morgan, Ipswich, U.K.); an $\mathrm{F}_{1}$ plant was then self-pollinated and a resulting multiple-flowering $\mathrm{F}_{2}$ plant was selected and back-crossed to the 'True French' inbred to obtain first backcross generation plants. The process of backcross pedigree breeding (Allard, 1960), using the 'True French' inbred as the recurrent parent, was continued through the sixth back-cross generation. Accession 1777, a true-breeding, multiple-flowering derivative from the sixth back-cross generation, therefore can be considered as nearly isogenic with 'True French', but, unlike that cultivar, its plants bear two flowers at some stem nodes.

Plants of Accession 1777 and 'True French' were intercrossed, and reciprocal $F_{1}$ plants were selfed and/or back-crossed. Seeds of the parents, filial, and back-cross generations were sown in flats, the inverse pyramid-shaped cells $3.5 \times 3.5 \mathrm{~cm}$ square at the top and $6 \mathrm{~cm}$ deep, filled with $50 \%$ peat and $50 \%$ vermiculite v/v on 15 Feb., 25 Mar., and 3 May 2010. The flats were placed in a chamber having 14-h day length, $27 \pm 2{ }^{\circ} \mathrm{C}$ by day and $20 \pm 2{ }^{\circ} \mathrm{C}$ at night until seedling emergence ( 4 to $6 \mathrm{~d}$ ), and then moved to a well-ventilated greenhouse. Six to $11 \mathrm{~d}$ later, the seedlings were transplanted to plastic pots filled with $6 \mathrm{~L}$ of a commercial potting medium containing $60 \%$ peat, $30 \%$ tuff, and $10 \%$ perlite $\mathrm{v} / \mathrm{v} / \mathrm{v}$ (Shaham, Giv'at 'Ada, Israel). Temperatures in the greenhouse were generally moderate, not lower than $8{ }^{\circ} \mathrm{C}$ at night and not exceeding $32{ }^{\circ} \mathrm{C}$ during the day, except in the last planting, when temperatures reached $35^{\circ} \mathrm{C}$. Day length ranged from $12 \mathrm{~h}$ in the first planting to $15 \mathrm{~h}$ in the last planting. Each plant was scored for number of flower buds produced at each node from the first to the 15th. Plants having only one flower per node were scored as "single-flowering" and those having one or more nodes bearing two flowers were scored as "multiple-flowering." Except as described later, the results obtained from the three plantings were similar enough to allow them to be pooled for presentation.

\section{Results and Discussion}

Plants of 'True French' $(n=20)$ were single-flowering, having produced one flower bud per leaf axil. Plants of Accession 1777 ( $\mathrm{n}=$ 21) were multiple-flowering, having each produced at least one axil out of the first 15 that bore two flower buds (Table 1). The earliest axil at which two flower buds were produced was the fifth (Table 2). Individual plants of Accession 1777 had one to seven nodes that produced two flower buds, averaging 3.9.

With one exception, all $\mathrm{F}_{1}$ plants $(\mathrm{n}=40)$ produced only one flower per axil; one plant had one axil with two flower buds (Table 1). In the back-cross to 'True French', all plants $(n=60)$ produced one flower per axil.

In the $F_{2}, 34$ of the 165 plants had one or more axils with two flowers (Table 1). The earliest axil to have two flowers was the fifth and, for these 34 plants, the average number of leaf axils having two flower buds was 2.9 (Table 2). In the back-cross to Accession 1777, 39 of the 77 plants had one or more axils bearing two flowers. The earliest axil to have two flowers was the fourth and, for these 39 plants, the average number of leaf axils having two flower buds was 2.7 .

The number of single-flowering to multiple-flowering plants did not deviate significantly from ratios of $3: 1$ in the $F_{2}$ and $1: 1$ in the back-cross to the multiple-flowering parent (Table 1). These results would be expected if multiple flowering is conferred by a single recessive gene. This gene is hereby designated multiple flowering, symbol $m f$.

When two flower buds were produced at the same node, they were almost never of the same size (Fig. 1). Sometimes two males were produced, sometimes a male with a smaller female or a female with a smaller male. The second, smaller flower at any given node often had a small leaflet adnate to its pedicel. On one occasion, it was noted that the male was larger initially, but the female overtook it, reaching anthesis ahead of it.

The production of more than one flower per axil appeared to be independent of sexuality. The secondary bud could be of the same sex as the primary bud or different (Fig. 1) and, for a given axil, the proportion of male versus female flowers among the secondary buds appeared to be no different from among the primary buds. Although there was no 
Table 1. Segregation for number of flower buds at individual leaf axils in the cross of 'True French' (singleflowering) and Accession 1777 (multiple-flowering).

\begin{tabular}{llcccccc}
\hline & & \multicolumn{2}{c}{ Number of plants } & Expected & & \\
\cline { 3 - 6 } Generation & \multicolumn{1}{c}{ Description } & Single flowering & Multiple flowering & ratio & Chi-square & $P$ \\
\hline $\mathrm{P}_{1}$ & True French & 20 & 0 & - & - & - \\
$\mathrm{P}_{2}$ & Accession 1777 & 0 & 21 & - & - & - \\
$\mathrm{F}_{1}$ & $\mathrm{P}_{1} \times \mathrm{P}_{2}$ & 20 & 0 & - & - & - \\
$\mathrm{F}_{1}$ & $\mathrm{P}_{2} \times \mathrm{P}_{1}$ & 19 & 1 & - & - & - \\
$\mathrm{F}_{1}$ & Total & 39 & 1 & - & - & - \\
$\mathrm{F}_{2}$ & $\mathrm{P}_{1} \times \mathrm{P}_{2}, \otimes$ & 81 & 19 & $3: 1$ & 1.920 & 0.17 \\
$\mathrm{~F}_{2}$ & $\mathrm{P}_{2} \times \mathrm{P}_{1}, \otimes$ & 50 & 15 & $3: 1$ & 0.128 & 0.72 \\
$\mathrm{~F}_{2}$ & Total & 131 & 34 & $3: 1$ & 1.699 & 0.18 \\
$\mathrm{BC}_{1}$ & $\mathrm{P}_{1} \times\left(\mathrm{P}_{1} \times \mathrm{P}_{2}\right)$ & 60 & 0 & - & - & - \\
$\mathrm{BC}_{1}$ & $\mathrm{P}_{2} \times\left(\mathrm{P}_{2} \times \mathrm{P}_{1}\right)$ & 38 & 39 & $1: 1$ & 0.013 & 0.90 \\
\hline
\end{tabular}

Table 2. Frequency distribution of leaf axils having two flower buds.

\begin{tabular}{lccccccccccccccc}
\hline & \multicolumn{11}{c}{ Leaf axil number } \\
\cline { 2 - 14 } Generation & 1 & 2 & 3 & 4 & 5 & 6 & 7 & \multicolumn{11}{c}{9} & \multicolumn{10}{c}{10} & 11 & 12 & 13 & 14 & 15 \\
\hline $\mathrm{P}_{2}$, Accession 1777 & 0.0 & 0.0 & 0.0 & 0.0 & 14.3 & 23.8 & 9.5 & 38.1 & 9.5 & 38.1 & 33.3 & 42.9 & 42.9 & 66.7 & 66.7 \\
$\mathrm{~F}_{2}$ (total) & 0.0 & 0.0 & 0.0 & 0.0 & 20.6 & 41.2 & 23.5 & 20.6 & 32.4 & 26.5 & 26.5 & 23.5 & 14.7 & 32.4 & 32.4 \\
$\mathrm{BC}_{1}$ to Accession & 0.0 & 0.0 & 0.0 & 7.7 & 15.4 & 17.9 & 12.8 & 25.6 & 33.3 & 30.8 & 10.3 & 12.8 & 12.8 & 38.5 & 56.4 \\
$\quad 1777$ & & & & & & & & & & & & & & & \\
\hline
\end{tabular}

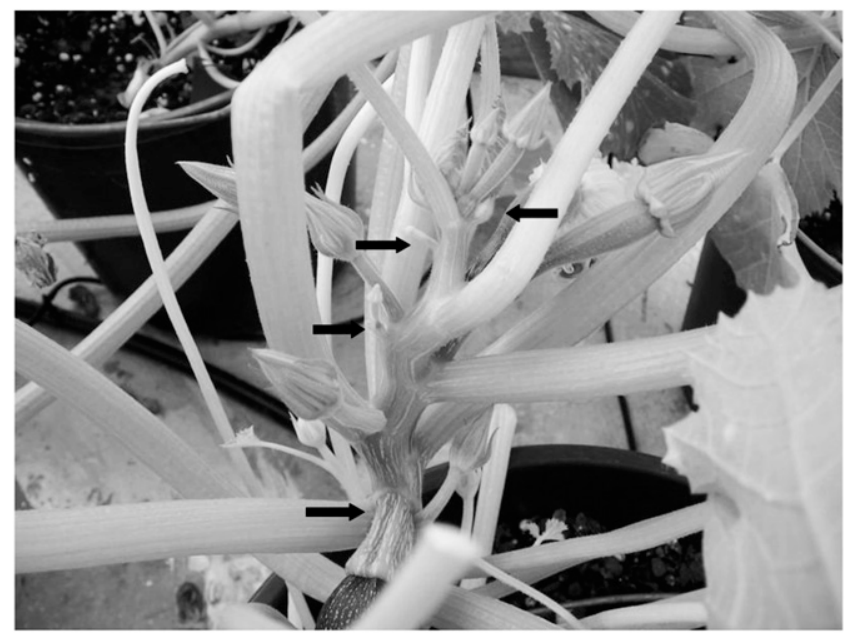

Fig. 1. Plant of zucchini Accession 1777 showing some leaf axils, indicated by arrows, with two flower buds. The most apical arrow points to an axil from which arise a larger pistillate bud (left) and a smaller staminate bud (right). The most basal arrow points to a leaf axil bearing a peduncle with base of young fruit (left) and a staminate flower bud (right). The two intermediate arrows point to axils from which arise a smaller pistillate bud (left) and a larger staminate bud (right). interdependence between these characteristics, multiple-flowering expression tended to increase at successive axils (Table 2); an increasing gradient has also been documented for female tendency (Kubicki, 1970; Nitsch et al., 1952; Shifriss, 1961). Moreover, plants of Accession 1777 had an average of 4.6 and 4.3 multiple-flowering axils in the February and March seedings, respectively, but only 2.8 in the May seeding. This observation is reminiscent of results showing that femaleness, too, is decreased by high temperatures, low moisture availability, and long days (Nitsch et al., 1952; Robinson and Decker-Walters, 1997).

Cucurbita pepo plants often have more than one potential meristem per axil (Robinson and Decker-Walters, 1997). One can develop into a flower bud, another into a shoot, another into a tendril, and another into an adventitious root. The development or lack of development of these meristem initials is dependent on the macro- and microenvironment and genetic factors. For example, roots usually will not develop unless the particular stem node involved rests on moist ground. Tendrils develop on vine, $b u / b u$, but not bush, $B u /-$, plants. The amount of branching is an inherited trait, with some genotypes such as 'True French' being non-branching. It is not known whether the multiple-flowering trait is based on the production of more initials or the redirection of existing initials, be they for branch, tendril, or root, to flower bud initiation.

\section{Literature Cited}

Allard, R.W. 1960. Principles of plant breeding. John Wiley \& Sons, New York, NY. p. 156.

Kubicki, B. 1970. Androecious strains of Cucurbita pepo L. Genet. Polon. 11:45-51.

Nitsch, J.P., E.B. Kurtz, J.L. Liverman, and F.W. Went. 1952. The development of sex expression in cucurbit flowers. Amer. J. Bot. 39:32-43.

Paris, H.S. 1996. Summer squash: History, diversity, and distribution. HortTechnology 6:6-13.

Paris, H.S. and D.N. Maynard. 2008. Cucurbita spp. squash, pumpkin, gourds, p. 292-299. In Janick, J. and R.E. Paull (eds.). The encyclopedia of fruits \& nuts. CABI, Wallingford, Oxfordshire, UK.

Robinson, R.W. and D.S. Decker-Walters. 1997. Cucurbits. CAB International. Wallingford, Oxon, UK. p. 6-9, 17-18.

Shifriss, O. 1961. Sex control in cucumbers. J. Hered. 52:5-12. 